\title{
O capital social dos gestores de organizações não governamentais
}

\author{
The social capital of non-governmental organizations managers
}

\author{
Marciano Bruch ${ }^{1}$ \\ Derli Luís Angnes ${ }^{2}$
}

\begin{abstract}
Resumo
Apesar do avanço tecnológico e econômico do mundo no último século, ainda existem muitas pessoas que necessitam de solidariedade. Em razão disso, as Organizações Não Governamentais (ONGs) foram vistas como entidades voluntárias capazes de suprir as falhas deixadas pelo Estado nos setores sociais. Somente no Brasil há mais de 350.000 organizações desse tipo atuando em setores como educação, saúde, cultura e recreação, assistência social, religião, entre outros. Nesse sentido, o estudo tem como objetivo identificar e medir as dimensões do capital social dos gestores das unidades de uma organização de voluntariado. Para tanto, aplicou-se uma survey com 30 gestores de unidades da Parceiros Voluntários, no estado do Rio Grande do Sul. Na análise dos dados, foram utilizadas técnicas estatísticas, como análise descritiva e análise fatorial. Os resultados permitiram identificar três dimensões de capital social presentes nos gestores da Parceiros Voluntários: dimensão credibilidade, relacionamento e proximidade. O capital social nas três dimensões superou os $70 \%$, evidenciando um bom desempenho dos gestores da ONG Parceiros Voluntários.
\end{abstract}

Palavras-chave: Organizações Não Governamentais.Terceiro Setor. Capital Social.Voluntariado. Gestores.

\begin{abstract}
Despite the technological and economic advancement of the world in the last century, there are still many people who need solidarity. As a result, Non-Governmental Organizations (NGOs) were seen as entities capable of filling the gaps left by the State in the social sectors. There are over 350,000 such organizations in Brazil, operating in sectors such as education, health, culture and recreation, social welfare, religion and others. In this sense, the present study aims to identify and measure the social capital of managers of a voluntary organization. Therefore, a survey with 30 managers of the NGO ParceirosVoluntáriosin the state of Rio Grande do Sul was developed. In the data analysis, statistical techniques were used, such as descriptive analysis and factor analysis. The results allowed identifying three dimensions of social capital present in the managers of the Volunteer Partners: Dimension Credibility, Relationship and Proximity. The Social Capital in the three dimensions surpassed $70 \%$, evidencing a good performance of the managers of the NGO ParceirosVoluntários.
\end{abstract}

Keywords: Non Governmental Organizations. Third Sector. Share Capital. Volunteers. Managers.

\section{Introdução}

Apesar do avanço tecnológico e econômico do mundo no último século, ainda existem muitas pessoas que necessitam de solidariedade, especialmente nos países em desenvolvimento. Atualmente, existem milhões de organizações sem fins lucrativos e de voluntariado que realizam trabalhos sociais. Em todo o mundo, estima-se 140 milhões de pessoas envolvidas na atividade. Somente no Brasil há mais de 350 mil organizações desse tipo, atuando em setores como: educação, saúde, cultura e recreação, assistência social, religião, entre outros (PARCEIROS VOLUNTÁRIOS, 2011).

No Brasil, o termo ONG (Organização Não Governamental) refere-se a um tipo peculiar de organização da sociedade. Trata-se de um agrupamento de pessoas, estruturadas sob a forma de uma

Mestre em Administração pela Universidade de Santa Cruz do Sul - UNISC. Brasil. Afiliação: Faculdade de Tecnologia La Salle - Estrela (RS). Lattes: http://lattes.cnpq.br/2139146671730183. Email: marciano.bruch@gmail.com

2 Mestre em Administração pela Universidade de Santa Cruz do Sul (UNISC). Brasil. Afiliação: UNISC. Lattes: http://lattes.cnpq. br/8252660541407330. Email: derli.angnes@gmail.com 
instituição da sociedade civil, que se declara ser sem fins lucrativos, pois tem como objetivo as causas sociais (CAMARGO et al., 2001).Um dos aspecto que fortalece o engajamento nesse tipo de organização é o capital social, cuja terminologia é relativamente nova para um conceito antigo, que é de participação cívica, cidadania, colaboração, cooperação e confiança. O capital social é composto por elementos que são necessários para torná-lo mais compreensível (DREYER; JOHANNPETER, 2008). Ressalta-se, ainda, a importância de avaliações quantitativas para compreender o capital social no desenvolvimento econômico e social (GENARI, 2010). Assim sendo, este estudo foi realizado na intenção de buscar identificar as dimensões do capital social dos gestores de uma ONG. Entende-se que as dimensões do capital social dos gestores são fatores que impactam na gestão das Organizações Não Governamentais para o alcance dos seus objetivos sociais. Os gestores precisam ser capazes de usar seu capital social para estabelecer contatos e atrair possíveis financiadores e voluntários, de modo que a ONG consiga implementar os seus projetos por meio de recursos humanos engajados socialmente, aspecto que envolve a compreensão do desempenho e identificação das dimensões que compõe o capital social dos gestores desse tipo de organização. Coloca-se, portanto, o seguinte problema de pesquisa: Quais seriam as dimensões do capital social dos gestores da ONG Parceiros Voluntários?

Nesse sentido, o artigo tem como objetivo identificar e medir as dimensões do capital social dos gestores das unidades de uma organização de voluntariado; e Tcomo objeto de análise tem-se a organização Parceiros Voluntários, que se define como uma organização não governamental, sem fins lucrativos e apartidária. Criada em 13 de janeiro de 1997, por iniciativa do empresariado e com a missão de mobilizar, articular, formar pessoas e instituições, estimulando redes e parcerias para o atendimento das demandas sociais, atualmente, a Parceiros Voluntários conta com 51 unidades espalhadas por diferentes regiões do estado do Rio Grande do Sul, mobilizando mais de um milhão de pessoas ao ano em média (PARCEIROS VOLUNTÁRIOS, 2011).

A relevância do estudo é de caráter prático e social, pois, por um lado, identifica e mede as dimensões do capital social dos gestores, dando contribuições de ordem gerencial a esse tipo de organização; e, por outro, contribui com dados e informações para o aprimoramento da atividade da ONG em seus objetivos e ações sociais.

\section{Referencial teórico}

Para De Deus et al. (2009), "não existe consenso ainda acabado, entre os estudiosos, sobre o capital social, por se tratar de temática empírica e de complexa mensuração em que cada caso evidencia uma experiência única e cada pesquisador mobiliza sua própria percepção e forma de análise". Porém, identifica-se que o termo capital social está sendo utilizado cada vez mais, com o objetivo de explicar o desenvolvimento social, econômico e a cooperação entre indivíduos. O termo capital social é definido e analisado de diferentes maneiras, sendo que, em algumas circunstâncias, ele consiste em redes de relações de indivíduos; em outras situações, significa a taxa ou o grau de confiança entre membros de uma organização, ou em relação à comunidade na qual estão inseridos (BORGES, 2009).

Capital social é uma terminologia nova para um conceito antigo, que é de participação cívica, cidadania, colaboração, cooperação e de confiança. O capital social é composto por elementos que são necessários para facilitar e procurar torná-lo mais tangível. Portanto, para fomentar esse capital social, requer-se um conjunto de ações, como a confiança, a solidariedade, a cooperação, a identificação social, tanto de um indivíduo como também entre organizações (DREYER; JOHANNPETER, 2008).

O capital social pode ser compreendido como uma agregação de recursos que são ligados a uma associação, ou grupo, que permite a cada um dos seus membros o benefício do capital de propriedade coletiva. O capital social não é um ganho natural, mas algo que deve ser trabalhado em uma base constante. Ele é o produto de estratégias de investimento, individuais ou coletivas, conscientes ou inconscientes, com o intuito de estabelecer ou reproduzir relações sociais que são diretamente utilizáveis no curto ou longo prazo (BOURDIEU, 1986). Xavier et al. (2013) evidenciam, a partir de seus estudos, a importância que ele exerce como fator propulsor da articulação dos agentes locais em prol do desenvolvimento regional. 
É possível ver duas perspectivas principais nos estudos sobre capital social: o individual e o coletivo. Essas duas perspectivas têm como base verificar qual o nível de análise que será favorecido pelos resultados do capital social (LIN, 2001). Para Wegner (2005), a primeira linha de pensamento sobre o assunto referese ao capital social como recursos (informações, ideias e apoio) que os indivíduos adquirem em virtude de outras pessoas, ou seja, procura tratar o capital social como um "recurso de agentes" derivados de estruturas sociais específicas. A segunda abordagem refere-se ao capital social como a natureza e a extensão do envolvimento de um indivíduo em várias redes informais e organizações formais.

Ainda que os resultados de um indivíduo possam favorecer o grupo, ou comunidade, e vice-versa, e que o capital social coletivo possa influenciar o capital social individual, as duas perspectivas necessitam de análises diferentes. O capital social como um bem individual não é algo que pertença exclusivamente a uma pessoa, Ele é chamado de capital social individual por acabar dependendo da relação com o outro, além de que os estudos que tratam dessa perspectiva acabam se interessando nessas relações dos indivíduos como atores e nos recursos sociais que nelas são encontrados (BORGES, 2009). Como exemplo de estudos na perspectiva do capital social como um bem individual, pode-se citar os trabalhos de Granovetter (1973), que falam sobre a importância dos contatos da rede de relações de um indivíduo na sua busca de empregos.

Já na análise do capital social como um bem público, tem-se autores, como Bourdieu (1986), Coleman (1990), Fukuyama (1996) e Putnam (2002), que focam as relações internas de um grupo (organização, região, nação, classe social). Eles analisaram como as normas e as crenças de um grupo podem, ou não, facilitar as relações sociais.

Embora o termo capital social seja abordado desde o início do século XIX, ele recebeu destaque a partir de 1990, quando o Banco Mundial passou a estudar o tema e vinculá-lo às questões relacionadas à pobreza, além de utilizar o conceito na avaliação de projetos de desenvolvimento submetidos à instituição. O Banco Mundial, por exemplo, tem como objeto de estudo as fontes de capital social (família, sociedade civil, comunidades, etnia, setor público e gênero) e as relações possíveis entre capital social e várias questões, como crime e violência, economia, comércio, migração e educação. Utilizam-se avaliações quantitativas para compreender o papel do capital social no desenvolvimento econômico e social (GENARI, 2010).

O Banco Mundial associa o capital social a uma instituição envolvida com as relações e normas de uma sociedade, nas quais é definida a intensidade de sua interação social. Ainda segundo a entidade, o capital social é imprescindível para o desenvolvimento das sociedades que atuam de forma sustentável, elencando as fontes mais importantes de capital social: (1) as famílias, consideradas a forma de maior importância para a geração de capital social; (2) as comunidades: integrando vizinhos, grupos e amigos, e gerando importante contribuição se trabalharem juntos para o bem comum; (3) as empresas: essa fonte de capital comum; (4) a sociedade civil: considerada importante por sua capacidade de unir forças para buscar melhorias concretas; (5) o setor público: imprescindível para trazer o bem-estar para a sociedade; (6) o gênero: tornando-se exemplo o fato de que, no Brasil, o segmento feminino é o que mais desponta (DE DEUS et al., 2009).

O Banco Mundial (2013) afirma que estudiosos trabalhando com ambas as tradições conceituais concordam que é importante reconhecer que o capital social não é uma entidade única, mas de natureza multidimensional. Durante os últimos anos, a ideia de capital social tem gozado de um crescente prestígio nas ciências sociais, tanto na literatura teórica, quanto na literatura aplicada (GENARI, 2010).

O aumento da notoriedade e do uso do termo capital social aconteceu na década de 1990, e pode se atribuir esse aumento a Robert Putnam. Em sua obra "Comunidade e democracia: a experiência da Itália moderna", o autor questiona as variações do desempenho entre governos democráticos e descreve as diferenças relacionadas ao desenvolvimento entre as Regiões Norte e Sul da Itália, concluindo que se devem à maior presença de capital social na Região Norte daquele país. Com isso, o seu conceito de capital social se tornou um dos mais conhecidos. O autor afirma que "o capital social diz respeito a características de organização social como confiança, normas e sistemas, que contribuem para aumentar a eficiência da sociedade facilitando ações coordenadas" (PUTNAM, 2002, p. 177). 
O capital social não pode ser configurado como objeto de domínio de uma área particular (PEREIRA, 2004). O aumento de capital social, incluindo o incremento do empreendedorismo social, significa o aumento de empoderamento das populações, isto é, da sua possibilidade e capacidade de influir nas decisões públicas. De modo geral, o conceito converge entre autores em alguns pontos, como a existência de uma rede de relações sociais ligadas a um objetivo comum, o recurso dos indivíduos para alcançarem seus interesses por meio do coletivo, da confiança e da cooperação entre pessoas dentro de uma rede. Assim como o capital físico, financeiro e humano, o capital social também pode produzir riqueza para a organização, permitindo a realização de atividades que, na sua ausência, não seriam possíveis, ou seriam realizadas a custos mais elevados (CABREIRA, 2002).

O capital social possui atributos, e essas características podem ser subdivididas em três dimensões distintas que, embora sejam abordadas analiticamente de forma separada, possuem grande conexão: dimensão estrutural, dimensão relacional e dimensão cognitiva (NAHAPIET; GHOSHAL, 1998).

A dimensão estrutural refere-se ao padrão de conexão entre os atores, incluindo conexões e configurações da rede que descreve o padrão de ligações em termos de mensuração, tais como: densidade, conectividade, hierarquia e adequação organizacional. A dimensão relacional se refere aos ativos que são criados e alavancados por meio de relacionamento, incluindo atributos como identificação, confiança, normas, sanções, obrigações e expectativas. Já a dimensão cognitiva se caracteriza por visões compartilhadas, interpretações e sistemas de significados, como a linguagem, o código e as narrativas (NAHAPIET; GHOSHAL, 1998).

Em relação à dimensão relacional do capital social, existem quatro fases: a confiança, as normas, as obrigações, as expectativas e a identificação. A dimensão relacional focaliza o papel dos laços diretos entre atores com relação aos conteúdos e suas diversidades (NAHAPIET; GHOSHAL, 1998).

A dimensão confiança foi analisada por pesquisadores a partir de diferentes perspectivas e múltiplas definições (ALVES, 2016). A confiança é a crença de que o resultado das ações de um indivíduo será adequado do ponto de vista de outro indivíduo. Já as normas representam um grau de consenso no sistema social. Além disso, essas normas são definidas pelas pessoas, passando a ser referencial para aquilo que é certo ou errado (NAHAPIET; GHOSHAL, 1998).

A dimensão cognitiva reporta-se aos recursos que são providos por representações, interpretações e sistema de significados. Esta representa os recursos estabelecidos e o compartilhamento de significados entre membros da rede (NAHAPIET; GHOSHAL, 1998).

\subsection{Mensuração do Capital Social}

Uma das grandes dificuldades encontradas pelos autores em relação ao capital social é referente à sua mensuração, ou seja, a avaliar o nível de capital social de uma pessoa, de um grupo ou comunidade. Para isso, exige-se que estes fatores estejam bem definidos. Os esforços de mensuração vêm evoluindo e ganhando cada vez mais consistência metodológica, cuja discussão avança à medida que se passa do campo de exemplificações do capital social para o da construção de concepções teóricas mais detalhadas (JACOBI et al., 2006). O problema da mensuração do capital social é um tema com o qual os pesquisadores da área se debatem. Além das questões teóricas envolvidas, existem persistentes dificuldades na disponibilidade de informações (MONASTÉRIO, 2002).

A mensuração do capital social é discutida como um ponto crítico por vários especialistas da área. Nas duas últimas décadas, diferentes instrumentos e indicadores foram utilizados para a mensuração do capital social, porém muitos desses não foram desenvolvidos especificamente para a investigação deste tipo de capital (GENARI, 2010).

Existem na literatura diversas modalidades e diferentes metodologias relacionadas à mensuração do capital social, que incluem desde relações informais e organizações formais, como averiguar o nível de confiança interpessoal (social) e as atitudes favoráveis à cooperação com os outros, intensidade de relações familiares e de vizinhança, a participação comunitária e religiosa (SCHMIDT, 2004). Os instrumentos de mensuração do capital social devem ser específicos e adequados a cada realidade (PEREIRA, 2004). 
$\mathrm{Na}$ tentativa de conceber uma teoria de capital social, distinguem-se dois elementos conceituais principais para aferição e mensuração de capital social como um ativo nas redes: recurso enraizado e localização na rede. O primeiro volta-se para a qualidade e o valor dos recursos, tais como: riqueza, poder, status, entre outros, acessados por indivíduos nas suas redes e vínculos. Os indicadores aí associados dizem respeito à amplitude, qualidade, variedade e composição dos recursos (LIN, 2001). O segundo, por sua vez, volta-se para a identificação de pontes, ou acesso a pontes, que geram benefícios e retornos, como proposto por Granovetter (1973) com seu conceito de vínculos fracos, explorado por Burt (1992) com os "vazios estruturais".

Grootaert (2003) apresenta um instrumento denominado Questionário Integrado para Medir o Capital Social (QI-MCS), cujo objetivo é fornecer uma base para a medição das diferentes dimensões do capital social, descritas pelo Banco Mundial. Essa ferramenta tem como foco a sua aplicação em países em desenvolvimento, cujos resultados obtidos por meio da sua utilização produzem o conhecimento das dimensões sociais relacionadas ao desenvolvimento econômico.

Outro modelo para medir o capital social é proposto pelo Banco Mundial, que divide o questionário em categorias e variáveis. As dimensões estruturais e cognitivas do capital social: (a) grupos e redes, isto é, grau de participação em grupos, organizações, redes ou associações, além do nível de confiança e cooperação nas relações sociais com vizinhos e amigos; (b) confiança e solidariedade, isto é, o grau de confiança e solidariedade entre os membros da comunidade. Já os principais meios de operacionalização do capital social, são: (a) a ação coletiva e cooperação, que é o grau de participação das pessoas em ações coletivas em sua comunidade; (b) informação e comunicação, isto é, o grau de acessibilidade a informações; (c) coesão social e inclusão, isto é, grau de coesão social e inclusão, e fatores que as dificultam, como o grau de conflitos e violência na comunidade; e (d) empoderamento e ação política, que é a participação em protestos públicos, votação, grau de controle da própria vida, confiança no governo e instituições públicas. Vale ressaltar que o questionário do Banco Mundial baseia-se nas impressões das pessoas da referida comunidade em relação a essas variáveis. IsTo pode se tornar extremamente insólito, pois as pessoas têm impressões muito pessoais a respeito de satisfação, confiança e solidariedade (BANCO MUNDIAL, 2013).

O capital social envolve também fatores qualitativos locais. Assim, quando se trata da mensuração do capital social, pode-se enfrentar dificuldades, e ainda se necessita de uma combinação de medidas para encontrar resultados fiéis com a realidade da comunidade analisada. Observa-se que os estudiosos concordam que é importante reconhecer que o capital social não é uma entidade única, mas de natureza multidimensional (SEHNEM; MACKE, 2011).

\section{Metodologia}

Para que haja o correto entendimento da metodologia e dos resultados da pesquisa, torna-se imprescindível a definição conceitual e operacional dos principais termos e variáveis que serão utilizados ao longo do trabalho científico (MARTINS, 2002). Portanto, com o propósito de atingir ao objetivo deste estudo, uma pesquisa descritiva e com caráter quantitativo, desenvolveu-se uma survey com 30 gestores de unidades da Parceiros Voluntários no estado do Rio Grande do Sul. A escolha dessa ONG se deu por conveniência e pela proximidade de acesso para o pesquisador. A survey é um procedimento para coleta de dados primários a partir de indivíduos. Os dados podem variar entre crenças, opiniões, atitudes e estilos de vida até informações gerais (HAIR et al., 2009).

O questionário de pesquisa foi composto por questões abertas e fechadas, sendo as questões abertas de caracterização do entrevistado e da unidade a que o gestor está vinculado. As questões fechadas representam variáveis do capital social e compreendem 22 questões afirmativas com base nas referências de mensuração de Nahapiet e Ghoshal (1998) e Grootaert (2003), em que o respondente deveria indicar a resposta que mais se aproximava da sua realidade, optando por uma escala Likert de cinco pontos, desde discordo totalmente até concordo totalmente.

Concluída a etapa de elaboração do questionário, o questionário foi testado antes de utilizá-lo de uma maneira definitiva. Realizou-se um pré-teste do instrumento com dois gestores, selecionados por indicação da coordenação da ONG Parceiros Voluntários. A aplicação do pré-teste tem o objetivo de 
evidenciar possíveis falhas no questionário, como de inconsistência nas informações, complexidade das questões, linguagem complexa aos respondentes da pesquisa e, inclusive, se o número de questões é adequado. Após a verificação das falhas, deve-se realizar a reformulação do questionário, alterando, incluindo ou eliminando possíveis itens. O pré-teste pode ser aplicado mais de uma vez, tendo em vista seu aprimoramento e o aumento de sua validez (LAKATOS; MARCONI, 2010).

Os gestores receberam a versão-teste do questionário por correio eletrônico e opinaram qualitativamente sobre a clareza e pertinência das questões. Após a opinião e análise dos gestores que realizaram o pré-teste, constatou-se que não haveria a necessidade de realizar nenhuma alteração no questionário desenvolvido, pois o único aspecto mencionado pelos respondentes foi que algum gestor poderia não ter o número de voluntários cadastrados na unidade, mas, nesse caso, poderia obter-se a informação junto à coordenação da ONG.

O universo do estudo é formado pelo número total de unidades da Parceiros Voluntários que estão em funcionamento no estado do Rio Grande do Sul. Segundo dados recebidos da coordenação estadual da Parceiros Voluntários em julho de 2012, essa relação constava de 53 unidades, das quais uma encontravase inativa e outra executava somente um programa de voluntariado, levando a uma população de 51 unidades.

A coleta de dados foi realizada por meio do envio de questionário de pesquisa em formato digital ao gestor de cada unidade. Após contatos telefônicos e por correio eletrônico, obteve-se o retorno de 30 questionários, que constituem a amostra final de pesquisa para a realização das análises.

Os dados coletados foram analisados quantitativamente utilizando-se estatística descritiva, que é a etapa inicial da análise, utilizada para realizar a descrição e o resumo dos dados da pesquisa. Posteriormente, empregou-se a análise fatorial que, segundo Hair et al. (2009), é uma técnica estatística que pode sintetizar as informações de um grande número de variáveis em um número menor de variáveis ou fatores, facilitando a realização das análises do estudo. A análise fatorial foi primordial para identificar as dimensões que compõem o capital social da ONG Parceiros Voluntários. Também foi empregado teste de diferenças de médias usando o capital social.

Após a análise das dimensões do capital social, as unidades da Parceiros Voluntários foram divididas em três percentis (categorias), de acordo com o número de voluntários cadastrados, afim de comparálos em relação à média de desempenho para cada dimensão do capital social. Ressalta-se, por fim, a importância de avaliações quantitativas para compreender o papel do capital social no desenvolvimento econômico e social (GENARI, 2010).

\section{Análise do capital social dos gestores}

A ONG Parceiros Voluntários foi criada no estado do Rio Grande do Sul em janeiro de 1997, por iniciativa do empresariado e com a missão de mobilizar, articular, formar pessoas e instituições, estimulando redes e parcerias para o atendimento das demandas sociais. A Parceiros Voluntários define-se como uma organização não governamental, sem fins lucrativos e apartidária. Sua atuação se estende por mais de 80 municípios no estado. Dentre as 53 unidades da ONG existentes no estado, apenas 30 unidades, por intermédio dos seus gestores de unidade, responderam ao questionário, sendo que 24 delas funcionam em parceria com as Associações Comerciais ? do município, ou seja, possuem uma sala dentro da Associação Comercial (PARCEIROS VOLUNTÁRIOS, 2011).

Em relação ao público que respondeu os questionários, observa-se que todos são do sexo feminino. Em relação ao grau de instrução dos gestores das unidades, verificou-se que $63,3 \%$ dos entrevistados já concluíram sua graduação, ou ainda estão realizando uma pós-graduação. O que demonstra um nível de profissionalização e especialização dos gestores. Observa-se também que $26,6 \%$ estão cursando uma graduação, e apenas $10 \%$ possuem ensino médio completo.

Também se verificou que $80 \%$ dos gestores das unidades são contratados pelas Associações Comerciais $(\mathrm{ACl})$, isto é, além de desenvolverem o papel de gestor, obrigatoriamente desenvolvem mais alguma função na $\mathrm{ACl}$. Prova disto é que $56,6 \%$ dos entrevistados disponibilizam até 20 horas de trabalho semanais à Parceiros Voluntários, e no restante do tempo desenvolvem trabalhos pertinentes à Associação Comercial, o que pode dificultar a realização de projetos complexos. 
Dentre os entrevistados, ressalta-se que: 7 das 30 pessoas estão exercendo a função de gestor há menos de 1 ano nas suas respectivas unidades; 11 gestores estão nos seus cargos a menos de 4 anos; enquanto que 12 gestores ocupam seus cargos há mais de 4 anos. Observa-se que a maior concentração de tempo de exercício do cargo é maior que 1 ano de trabalho, mostrando que os gestores estão preocupados em fazer carreira.

Quando trata-se de tempo de funcionamento das unidades, 66\% funcionam há mais de 10 anos nas respectivas cidades. Esse percentual mostra que a Parceiros Voluntários não existe somente para realizar algum projeto pontual, mas sim para elaborar vários projetos, melhorando cada um deles quando necessário, conquistando credibilidade nas comunidades em que estão inseridas essas unidades.

$\mathrm{Na}$ identificação das dimensões do capital social dos gestores das unidades, foi utilizando um conjunto de 22 questões baseadas nos estudos de Grootaert (2003) e Nahapiet e Ghoshal (1998). Para sumarizar os dados, foi realizada uma análise fatorial, nome genérico que se dá a uma classe de métodos estatísticos multivariados, cujo objetivo principal é definir uma matriz de dados (HAIR et al., 2009).

O propósito geral da análise fatorial é encontrar uma maneira de condensar ou resumir a informação contida em diversas variáveis originais em um número menor possível de dimensões, tomando cuidado para que se tenha uma perda mínima de informações. O teste de esfericidade de Barlett, que verifica a hipótese nula de que a matriz de correlações é uma matriz identidade, comprovou que não há correlação entre variáveis, permitindo seguir com a análise fatorial do estudo (HAIR et al., 2009).

Na primeira análise fatorial das variáveis de capital social, foram encontrados quatro componentes, obtendo-se uma variância explicada de $75,93 \%$ das 14 variáveis originais. Com o objetivo de realocar, acrescentar, excluir e dar uma maior consistência à análise, foi realizada a rotação Varimax. Segundo Hair et al. (2009), é um dos métodos de rotação fatorial mais populares, em que a variância explicada por cada fator é alterada. Nesse último teste, verificou-se que o índice de adequação da amostra Kaiser-Meyer Olkin (KMO) foi de 0,705, considerado, segundo Hair et al. (2009), uma medida indicada como mediana, mostrando uma fatorabilidade dos dados. Foram encontrados três componentes, com uma variância explicada de $72,67 \%$ das variáveis originais.

Com base nas variáveis incluídas pela análise fatorial em cada um dos fatores destacados na tabela 1, optou-se por renomear os fatores utilizando a seguinte nomenclatura: dimensão credibilidade (Fator 1), dimensão proximidade (Fator 2), dimensão relacionamento (Fator 3).

Tabela 1 - Análise Fatorial

\begin{tabular}{|c|c|c|c|}
\hline Variáveis & Fator 1 & Fator 2 & Fator 3 \\
\hline A maior parte das pessoas desta cidade é honesta e merece confiança. & 0,841 & 0,206 & 0,131 \\
\hline De uma maneira geral, acredito que se pode confiar nas pessoas. & 0,841 & 0,328 & $-0,020$ \\
\hline $\begin{array}{l}\text { Nos finais de semana tenho o hábito de me encontrar com pessoas que não } \\
\text { sejam da minha casa. }\end{array}$ & 0,810 & $-0,101$ & 0,059 \\
\hline Existe um bom espirito participativo das pessoas da sua região. & 0,681 & 0,361 & 0,194 \\
\hline $\begin{array}{l}\text { Os voluntários cadastrados na unidade têm valores pessoais parecidos com os } \\
\text { meus. }\end{array}$ & 0,675 & 0,416 & 0,109 \\
\hline $\begin{array}{l}\text { Quando preciso de informações para tomar uma decisão profissional ou pessoal, } \\
\text { posso acionar meus contatos. }\end{array}$ & 0,136 & 0,870 & 0,040 \\
\hline $\begin{array}{l}\text { Os empresários com os quais tenho contato têm valores parecidos com os } \\
\text { meus. }\end{array}$ & 0,371 & 0,765 & 0,028 \\
\hline $\begin{array}{l}\text { Tenho uma relação próxima com as pessoas-chave nesta cidade (líderes } \\
\text { comunitários, empresariais, representantes políticos). }\end{array}$ & 0,213 & 0,706 & 0,444 \\
\hline $\begin{array}{l}\text { Quando vou às compras nas redondezas, é comum encontrar amigos ou } \\
\text { conhecidos. }\end{array}$ & 0,042 & 0,365 & 0,855 \\
\hline $\begin{array}{l}\text { Sou um membro ativo de grupos ou organizações locais (ex. Grupo de Dança, } \\
\text { Lions, Clubes de esporte, comunidade, etc). }\end{array}$ & 0,037 & $-0,274$ & 0,853 \\
\hline Tenho muitos amigos próximos. & 0,229 & 0,359 & 0,614 \\
\hline
\end{tabular}

Nota: Extraction Method: Principal Component Analysis. Rotation Method: Varimax with Kaiser Normalization. Rotation converged in 5 iterations.

Fonte: Elaborado pelos autores. 
Observa-se que, no componente 1, há variáveis sobre credibilidade (tanto relacionadas às pessoas da cidade como às pessoas de um modo geral) e variáveis relacionadas à honestidade das pessoas. Além disso, há questões relacionadas ao espírito participativo das pessoas. Considerando as variáveis que fazem parte desse componente, optou-se por nominá-lo como "dimensão credibilidade". Essa dimensão refere-se à existência de relações de confiança do gestor da unidade com a comunidade onde está inserido, o que o habilita a contatar essas pessoas e obter seu comprometimento para realizar ações relacionadas a Parceiros Voluntários. Além disso, quando os indivíduos estabelecem relações de confiança e credibilidade, torna-se mais fácil acessar e trocar informações que podem ser utilizadas para potencializar os resultados da unidade (NAHAPIET; GHOSHAL, 1998).

No componente 2, que possui três variáveis, destacam-se questões relacionadas à possibilidade de acionar a rede de contatos para a tomada de decisões por parte dos gestores, se os empresários possuem valores parecidos com os dos gestores e se possuem uma relação próxima com pessoas influentes na cidade onde vivem (como líderes comunitários, empresariais, representantes políticos). Esse componente foi denominado de "dimensão proximidade", pois se refere à característica do gestor da unidade de estabelecer relações próximas com as pessoas na comunidade onde atua. A proximidade entre os atores facilita o acesso às informações e faz com que haja maior interação. Quando essa dimensão do capital social dos gestores é reforçada, elas têm intimidade suficiente com seus contatos - empresários e pessoas influentes - para pedir apoio nas ações da Parceiros Voluntários. Além disso, essa proximidade também funciona como um fator que favorece o convencimento de novos voluntários para a realização das ações propostas (NAHAPIET; GHOSHAL, 1998).

Já o componente 3 possui três variáveis que dizem respeito ao nível de relacionamento do gestor com a comunidade onde atua (como demonstrado nas perguntas sobre sua participação em grupos ou organizações locais), o número de amigos próximos na comunidade e a possibilidade de encontrar amigos e conhecidos quando realiza atividades cotidianas na cidade, recebendo o nome de "dimensão relacionamento". Essa dimensão está vinculada à rede de relações e ao seu sistema social. Realizando um comparativo com as dimensões definidas por Nahapiet e Ghoshal (1998), os autores destacam a presença de algum elo entre pessoas envolvidas, como também se existe algum padrão de ligação. Essa "sociabilidade" do capital social pode ser o encontro com pessoas em espaços públicos, participação em eventos comunitários, tais como esportes ou cerimônias. Gestores que possuem essa dimensão do capital social em alto nível indicam possuir relações significativas na comunidade onde atuam, o que pode impactar significativamente na sua capacidade de mobilizar pessoas e estimular o engajamento em ações de voluntariado (GROOTAERT, 2003).

Após a definição das três dimensões do capital social, foram realizadas análises pertinentes ao capital social dos gestores. Inicialmente, apresenta-se a análise descritiva das dimensões de capital social, verificando a média de cada uma, valor relativo dentro da escala de cinco pontos e o desvio padrão, chegando aos resultados apresentados na tabela 2.

Tabela 2 - Dimensões do capital social

\begin{tabular}{lllll}
\hline Dimensões do Capital Social & Amostra & Média & Valor Relativo & Desvio Padrão \\
\hline Dimensão credibilidade & 30 & 3,5628 & $71 \%$ & 0,77790 \\
Dimensão proximidade & 30 & 3,8000 & $73 \%$ & 0,84350 \\
Dimensão relacionamento & 30 & 3,9222 & $78 \%$ & 0,79598 \\
\hline
\end{tabular}

Fonte: Elaborado pelos autores.

Observa-se na tabela 2 que, dos 30 gestores que responderam à pesquisa: na dimensão credibilidade, a média das variáveis foi de 3,56 pontos (71\%); na dimensão proximidade, foi de 3,80 pontos (73\%); e na dimensão relacionamento, de 3,92 pontos (78\%). Levando-se em consideração as médias apresentadas por dimensão de capital social para uma escala de 5 pontos, conclui-se que o capital social dos gestores das unidades pode ser considerado bom, pois alcança valores entre $71 \%$ a $78 \%$ na média das variáveis que compõe cada dimensão avaliada, dentro de uma escala de cinco pontos (100\%). Verifica-se também na 
tabela 2 que o desvio padrão é baixo, confirmando que as médias são representativas. Portanto, evidenciase que os respondentes são relativamente homogêneos em termos de capital social.

Após a análise das dimensões do capital social, as unidades foram divididas em três percentis, de acordo com o número de voluntários cadastrados em 2011, sendo que o $1^{\circ}$ percentil engloba 10 unidades da Parceiros Voluntários, que possuem até 283 (duzentos e oitenta e três) voluntários cadastrados, recebendo o nome de categoria I.O $2^{\circ}$ percentil engloba 10 unidades da Parceiros Voluntários, que possuem entre 284 (duzentos e oitenta e quatro) e 1013 (um mil e treze) voluntários cadastrados, recebendo o nome de categoria II. Já o $3^{\circ}$ percentil engloba 10 unidades da Parceiros Voluntários, que possuem mais de 1014 (um mil e quatorze) voluntários cadastrados, recebendo o nome de categoria III, conforme apresentado na tabela 3.

Tabela 3 - Categorias das unidades

\begin{tabular}{lcc}
\hline Categorias & Voluntários & N. ${ }^{\circ}$ de Unidades \\
\hline Categoria I & Menos de 284 voluntários & 10 unidades \\
Categoria II & De 284 até 1013 voluntários & 10 unidades \\
Categoria III & Mais de 1014 voluntários & 10 unidades \\
\hline
\end{tabular}

Fonte: Elaborado pelos autores.

A tabela 4 apresenta os resultados consolidados das médias, valor relativo e desvio padrão por dimensão do capital social dos gestores, comparando-as em relação à categoria das unidades supracitadas.

Tabela 4 - Comparativo entre dimensões e categorias

\begin{tabular}{lcccccc}
\hline \multirow{2}{*}{ Dimensão } & Média & \multirow{2}{*}{$\begin{array}{c}\text { Valor } \\
\text { Geral }\end{array}$} & \multirow{2}{*}{$\begin{array}{c}\text { Desvio } \\
\text { Relativo }\end{array}$} & Padrão & \multicolumn{3}{c}{ Média por categorias das unidades } \\
\cline { 6 - 7 } & & & $\mathbf{I}(\mathbf{N}=10)$ & II (N=10) & III (N=10) \\
\hline Dimensão Credibilidade & 3,5628 & $71 \%$ & 0,77790 & 3,1900 & 3,9250 & 3,5733 \\
Dimensão Proximidade & 3,8000 & $73 \%$ & 0,84350 & 3,3167 & 4,1000 & 3,9833 \\
Dimensão Relacionamento & 3,9222 & $78 \%$ & 0,79598 & 4,0000 & 4,3000 & 3,4667 \\
\hline
\end{tabular}

Fonte: Elaborado pelos autores.

Nas médias das dimensões por unidade, observa-se que, nas três dimensões, o capital social dos gestores de unidades de categoria II é maior que o capital social do gestor das categorias I e III. Isso revela que nas três dimensões do capital social dos gestores, os membros da categoria II são os que possuem o melhor resultado entre os demais gestores das outras categorias.

Uma vez que foram apresentadas estatísticas descritivas para as variáveis do estudo, optou-se por realizar outros testes que permitiram comparar os respondentes de acordo com determinadas características e que contribuem para aprimorar os resultados do estudo.

O teste Anova, para Hair et al. (2009), é uma análise de variância, sendo usada para examinar diferenças estatísticas entre médias de dois ou mais grupos. Os autores afirmam ainda que a Anova de um fator tem uma variável independente, e a Anova de $\mathrm{n}$ fatores pode ter duas ou mais variáveis independentes não métricas.

O teste Anova realizado constituiu-se na comparação do nível de capital social dos gestores das três categorias de unidades, cujos resultados estão apresentados na tabela 5. 
Tabela 5 - Teste de Anova

\begin{tabular}{|c|c|c|c|c|c|c|c|}
\hline \multirow[b]{2}{*}{$\begin{array}{l}\text { Variável } \\
\text { dependente }\end{array}$} & \multirow[b]{2}{*}{$\begin{array}{l}\text { (I) Tamanho } \\
\text { da unidade }\end{array}$} & \multirow[b]{2}{*}{$\begin{array}{l}\text { (J) Tamanho } \\
\text { da unidade }\end{array}$} & \multirow[b]{2}{*}{$\begin{array}{l}\text { Diferença } \\
\text { média (I-J) }\end{array}$} & \multirow[b]{2}{*}{$\begin{array}{l}\text { Erro } \\
\text { padrão }\end{array}$} & \multirow[b]{2}{*}{ Sig. } & \multicolumn{2}{|c|}{ Intervalo de confiança $95 \%$} \\
\hline & & & & & & $\begin{array}{c}\text { Limite } \\
\text { inferior }\end{array}$ & $\begin{array}{l}\text { Limite } \\
\text { superior }\end{array}$ \\
\hline \multirow{6}{*}{$\begin{array}{l}\text { Dimensão } \\
\text { credibilidade }\end{array}$} & \multirow{2}{*}{ I } & II & $-0,73500$ & 0,33162 & 0,086 & $-1,5572$ & 0,0872 \\
\hline & & III & $-0,38333$ & 0,33162 & 0,489 & $-1,2056$ & 0,4389 \\
\hline & \multirow{2}{*}{ II } & 1 & 0,73500 & 0,33162 & 0,086 & $-0,0872$ & 1,5572 \\
\hline & & III & 0,35167 & 0,33162 & 0,546 & $-0,4706$ & 1,1739 \\
\hline & \multirow{2}{*}{ III } & I & 0,38333 & 0,33162 & 0,489 & $-0,4389$ & 1,2056 \\
\hline & & II & $-0,35167$ & 0,33162 & 0,546 & $-1,1739$ & 0,4706 \\
\hline \multirow{6}{*}{$\begin{array}{l}\text { Dimensão } \\
\text { proximidade }\end{array}$} & \multirow{2}{*}{ I } & II & $-0,78333$ & 0,35550 & 0,089 & $-1,6648$ & 0,0981 \\
\hline & & III & $-0,66667$ & 0,35550 & 0,165 & $-1,5481$ & 0,2148 \\
\hline & \multirow{2}{*}{ II } & I & 0,78333 & 0,35550 & 0,089 & $-0,0981$ & 1,6648 \\
\hline & & III & 0,11667 & 0,35550 & 0,942 & $-0,7648$ & 0,9981 \\
\hline & \multirow{2}{*}{ III } & I & 0,66667 & 0,35550 & 0,165 & $-0,2148$ & 1,5481 \\
\hline & & II & $-0,11667$ & 0,35550 & 0,942 & $-0,9981$ & 0,7648 \\
\hline \multirow{6}{*}{$\begin{array}{l}\text { Dimensão } \\
\text { relacionamento }\end{array}$} & \multirow[b]{2}{*}{ I } & II & $-0,30000$ & 0,33123 & 0,641 & $-1,1213$ & 0,5213 \\
\hline & & III & 0,53333 & 0,33123 & 0,259 & $-0,2879$ & 1,3546 \\
\hline & \multirow{2}{*}{ II } & I & 0,30000 & 0,33123 & 0,641 & $-0,5213$ & 1,1213 \\
\hline & & III & $0,83333^{*}$ & 0,33123 & 0,046 & 0,0121 & 1,6546 \\
\hline & \multirow{2}{*}{ III } & 1 & $-0,53333$ & 0,33123 & 0,259 & $-1,3546$ & 0,2879 \\
\hline & & II & $-0,83333^{*}$ & 0,33123 & 0,046 & $-1,6546$ & $-0,0121$ \\
\hline
\end{tabular}

* A diferença média é significativa no nível 0.05

Fonte: Elaborado pelos autores.

$\mathrm{Na}$ tabela 5 , verifica-se que as três análises revelaram uma diferença significativa, sendo que a primeira delas aconteceu na dimensão credibilidade do capital social dos gestores das unidades de categoria II em relação aos gestores das unidades de categoria I.

A segunda diferença significativa ocorreu na dimensão proximidade, comparando-se especificamente os gestores da categoria II em relação aos gestores da categoria I. Outra diferença significativa ocorreu na dimensão relacionamento do capital social dos gestores nas unidades de categoria II comparando-se aos gestores das unidades da categoria III $(p<0,05)$. Pode-se considerar que, tanto na dimensão credibilidade como na dimensão proximidade, encontram-se diferenças significativas nas unidades de categoria I. Conclui-se que os gestores das unidades da categoria II são os gestores que possuem índice mais alto de capital social.

\section{Discussão}

Recapitulando Nahapiet e Ghoshal (1998), destacamos que o capital social possui atributos e que essas características podem ser subdivididas em três dimensões distintas, as quais, embora sejam abordadas analiticamente de forma separada, possuem grande conexão com os resultados desta pesquisa, que teve como objetivo identificar e medir as dimensões do capital social dos gestores das unidades de uma organização de voluntariado e permitiu identificar dimensões do capital social similares aos encontrados no estudo de Nahapiet e Ghoshal (1998). Ressalta-se que, devido ao fato de algumas variáveis se enquadrarem em mais de um componente ou dimensão, foram renomeados para: dimensão credibilidade, dimensão proximidade e dimensão de relacionamento.

$\mathrm{Na}$ análise de desempenho das dimensões do capital social da Parceiros Voluntários, verificou-se que o resultado ficou acima de $70 \%$ na escala para as três dimensões identificadas pelo estudo. Destacase o fato da análise ter identificado que unidades com grupos com 284 até 1013 voluntários atingiram melhores resultados no desempenho do capital social. Portanto, unidades com menos de 284 voluntários e unidades acima de 1013 voluntários passaram a ter um desempenho menor nas dimensões do capital social, aspecto que merece aprofundamento em estudos futuros. 
A dimensão credibilidade estabelece uma confiança social e a crença de que o resultado das ações de um indivíduo será adequado no ponto de vista de outro indivíduo (NAHAPIET; GHOSHAL, 1998). Caberá, portanto, a Parceiros Voluntários manter constantemente uma relação de credibilidade com a sociedade para que suas ações tenham reconhecimento e sejam aceitas com confiança perante a comunidade.

A dimensão proximidade entre os atores facilita o acesso às informações e faz com que haja maior interação. Quando essa dimensão do capital social dos gestores é reforçada, estes têm intimidade suficiente com seus contatos - empresários e pessoas-chave - para pedir apoio nas ações da Parceiros Voluntários. Além disso, essa proximidade também funciona como um fator que favorece o convencimento de novos voluntários para a realização das ações propostas (NAHAPIET; GHOSHAL, 1998).

Em relação à dimensão de relacionamento, reporta-se aos recursos que são providos por representações, interpretações e sistemas de significados. Esta representa os recursos estabelecidos, o compartilhamento de significados entre membros da rede. Apesar de se verificar no estudo um bom índice de capital social dos gestores, é imprescindível que a Parceiros Voluntários estimule seus gestores a desenvolverem o capital social em todas as dimensões apresentadas neste estudo. Na dimensão de relacionamento, também é conveniente desenvolver maneiras de incentivo. Nesse caso, especificamente, com a participação de outros grupos ou organizações locais. O fato de frequentar esses grupos ou locais dentro da comunidade também faz com que os gestores desenvolvam mais o seu capital social na dimensão de relacionamento (NAHAPIET; GHOSHAL, 1998).

O capital social também pode produzir riqueza para a organização, permitindo a realização de atividades que, na sua ausência, não seriam possíveis, ou seriam realizadas a custos mais elevados (CABREIRA, 2002).

\section{Conclusão}

O capital social é composto por elementos que são necessários para torná-lo mais compreensível (DREYER; JOHANNPETER, 2008). Partindo-se desse pressuposto, o objetivo de identificar e medir as dimensões do capital social dos gestores das unidades de uma organização de voluntariado foi atingido, obtendo-se como resultado que gestores das unidades pesquisadas na Parceiros Voluntários possuem um bom capital social, acima de $70 \%$ na média da escala das variáveis utilizadas em cada dimensão identificada: credibilidade, proximidade e relacionamento. A dimensão credibilidade é um componente básico de confiança do capital social. Básico, mas não único, tendo em vista que identifica também "outras formas de capital social, como as normas e as cadeias de relações sociais" (PUTNAM, 2002, p. 179, 180). A dimensão de relacionamento representa recursos estabelecidos, compartilhamento de significados entre membros da rede. Já a dimensão proximidade entre os atores facilita o acesso às informações e faz com que haja maior interação (NAHAPIET; GHOSHAL, 1998).

Como principal contribuição, este estudo tem relevância para a prática gerencial da ONG e para sua atividade social, identificando dimensões do capital social d que podem ser utilizados para aprimorar o desempenho de suas unidades e, consequentemente, melhorar a sua atuação em prol da solidariedade. Além disso, averiguou-sea importância da Parceiros Voluntários em trabalhar com seus gestores o aprimoramento e o desenvolvimento do seu capital social a partir das dimensões identificadas, de modo que influencie positivamente nos resultados de cada unidade da ONG. Também se destaca o fato da análise ter identificado que unidades com grupos a partir de 284 e até 1013 voluntários atingiram melhores resultados de desempenho nas dimensões do capital social identificadas. Ressalta-se ainda a relevância que o capital social tem para o desenvolvimento regional (XAVIER et al., 2013).

Cabe lembrar que administrar uma instituição sem fins lucrativos pode ser ainda mais "difícil", pois sua gestão muitas vezes não apresenta estrutura adequada, recursos financeiros, materiais e de pessoal suficientes. Todavia, é necessário que os gestores conheçam a sua área. Muitas ONGs propõem a discussão e a transformação de fatos econômicos e sociais, tendo seus gestores como agentes de mudanças. Um bom capital social facilita aos gestores a busca de novos voluntários e parcerias com a sociedade civil, criando um espaço propício para o seu fim (CAZZOLATTO, 2009). 
Em relação às limitações da pesquisa, relata-se o fato que dos 51 questionários aplicados ao universo delimitado pela pesquisa, apenas 30 foram respondidos por gestores, reduzindo sensivelmente a amostra e os resultados. Houve certa desconfiança por parte dos gestores com relação a fornecer informações pertinentes à unidade que está sob sua responsabilidade. Outra limitação do estudo foi a dificuldade na escolha do método para mensuração do capital social. A rotatividade dos gestores em algumas unidades também dificultou a obtenção de informações pertinentes às unidades.

Sugere-se para trabalhos futuros a elaboração de estudos específicos em unidades da Parceiros Voluntários que estão vinculadas às ACls, e unidades da Parceiros Voluntários que não possuem esse vínculo, buscando realizar um comparativo, principalmente em questões organizacionais, para identificar modelos de gestão aplicados por ambas. Também é pertinente realizar estudos comparativos entre organizações sem fins lucrativos e empresas privadas, para compreender os diferentes papéis do capital social em organizações diversas. Embora este estudo tenha tido o foco nos gestores das unidades, é importante realizar estudos futuros que incluam também os voluntários e uma amostra mais expressiva, com no mínimo 100 casos, procurando ampliar ainda mais a compreensão acerca das Organizações do Terceiro Setor no Brasil.

\section{Referências}

ALVES, C. A. Confiança e comprometimento e sua relação com o desempenho e a intenção de recompra do varejista dentro do canal de marketing. Revista Ciências Administrativas, v. 22, n. 1, p. 100-129, jan./jun.2016.

BANCO MUNDIAL. Informações gerais sobre Banco Mundial. Disponível em: <http://www.worldbank. org >. Acesso em: 08 mar. 2013.

BORGES, C. Como o capital social do empreendedor pode influenciar o processo de criação de uma empresa tecnológica? Santiago de Cali: Universidade Icesi, 2009.

BOURDIEU, P. The forms of capital. In: RICHARDSON, J. G. (Coord.). Handbook of theory and research for the sociology of education. New York: Greenwood Press, 1986. p. 241-258.

BURT, R. Structural holes: the social structure of competition. Cambridge: Harvard University Press, 1992.

CABREIRA, Z. Capital social como fator de sustentabilidade aos programas de desenvolvimento local, reflexões sobre uma prática: a experiência do Sebrae em Lagoa dos Três Cantos. 2002, 120 f. Dissertação (Mestrado em Administração) - Universidade Federal do Rio Grande do Sul. Porto Alegre: UFRGS, 2002.

CAMARGO, M. F.; SUSUKI, F. M.; SAKIMA, R. Y.; GHOBRIL, A. N. Gestão do terceiro setor no Brasil. São Paulo: Futura, 2001.

CAZZOLATO, N. K. As dificuldades de gestão das organizações não-governamentais. Revista da Faculdade de Administração e Economia, São Paulo, v. 1, p. 66-81, 2009.

COLEMAN, J. The Foundations if Social Theory. Cambridge: Harward University Press, 1990.

DE DEUS, M. H. B. M. et al. Formação do capital social em comunidade de baixa renda. Revista Ciências Administrativas, Fortaleza/CE, v. 15, n. 1, p. 57-84, jan./jun. 2009.

DREYER, L.; JOHANNPETER, M. E. P. O quinto poder: consciência social de uma nação. Porto Alegre: L\&PM, 2008.

FUKUYAMA, F. Confiança: as virtudes sociais e a criação da prosperidade. Rio de Janeiro: Rocco, 1996.

GENARI, D. Mensuração do Capital Social e comprometimento nas indústrias vitivinícolas do Vale dos Vinhedos associadas à Aprovale e Aprobelo: uma abordagem organizacional. 2010, $137 \mathrm{f}$. Dissertação (Mestrado em Administração) - Universidade de Caxias do Sul, Caxias do Sul: UCS, 2010. 
GRANOVETTER, M. The Strength of Weak Ties. American Journal of Sociology. Chicago, v. 78, n. 6 , p. 1360-1380, 1973.

GROOTAERT, C. Questionário integrado para medir capital social. Washington: Banco Mundial, 2003.

HAIR, J. J. R.; BLACK, W. C.; BABIN, B. J.; ANDERSON, R. E; TATHAM, R. L. Análise multivariada de dados. 6. ed. Porto Alegre: Bookman, 2009.

JACOBI, P. R. et al. Capital social e desempenho institucional. In: JACOBI, P. R.; FERREIRA, L. C. (Org.). Diálogos em ambiente e sociedade no Brasil. São Paulo: ANPPAS, 2006. p. 303-327.

LAKATOS, E. M.; MARCONI, M. A. Fundamentos de metodologia científica. 7. ed. São Paulo: Atlas, 2010.

LIN, N. Building a network theory of social capital. In: LIN, N.; COOK, C.; BURT, R. S. Social capital: theory and research. New York: Aldine de Gruyter, 2001. p. 3-30.

MARTINS, G. A. Manual para elaboração de monografias e dissertações. São Paulo: Atlas, 2002.

MONASTÉRIO, L. M. Capital social e a Região Sul do Rio Grande do Sul. 2002, 213 f. Tese

(Doutorado em Desenvolvimento Econômico) - Universidade Federal do Paraná. Curitiba: UFPR, 2002.

NAHAPIET, J.; GHOSHAL, S. Social capital, intelectual capital, and the organizational advantage.

Academy of Management Review. v. 23, p. 242-266, 1998.

PARCEIROS VOLUNTÁRIOS. 2011. Disponível em: <http://www.parceirosvoluntarios.org.br/>. Acesso em: 08 abr. 2011.

PEREIRA, J. C. R. Análise de dados qualitativos Estratégias metodológicas para ciências da saúde, humanas e sociais. 3 ed. São Paulo: Edusp, 2004.

PUTNAM, R. D. Comunidade e democracia: a experiência da Itália Moderna. Rio de Janeiro: FGV, 2002.

SCHMIDT, J. P. Os jovens e a construção do capital social no Brasil. In: KEIL, I. M.; BAQUERO, M. Democracia, juventude e capital social no Brasil. Porto Alegre: EdUFRGS, 2004. p. 147-179.

SEHNEM, A.; MACKE, J. Avaliação do capital social no ambiente universitário: uma experiência no Extremo-Oeste catarinense. Roteiro, Joaçaba, v. 36, n. 1, p. 81-104, jan./jun. 2011.

WEGNER, D. Redes horizontais de empresas no Rio Grande do Sul: um estudo dos fatores influentes na formação e desenvolvimento. 2005, 196 f. Dissertação (Mestrado em Administração) Universidade Federal de Santa Maria. Santa Maria: UFSM, 2005.

XAVIER, T. R.; RICHTER, A. S.; WITTMANN, M. L.; KERN, J.; INÁCIO, R. O. A relevância do capital social como elemento propulsor da articulação dos atores locais em prol do desenvolvimento regional. Revista Administração em Diálogo - RAD, São Paulo, v. 15, n. 1, p. 82-110, jan.-abr. 2013.

Submetido em: 29/09/2016

Aprovado em: 21/10/2017 